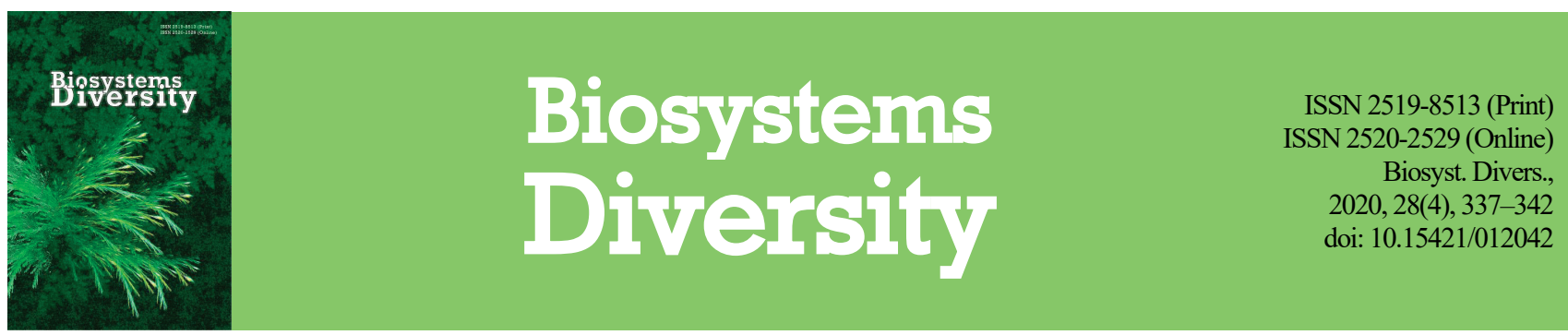

\title{
Features of exogenous development of Trichuris globulosa (Nematoda, Trichuridae)
}

\author{
V. O. Yevstafieva, V. V. Melnychuk, N. S. Kanivets, N. I. Dmitrenko, L. P. Karysheva, S. V. Filonenko \\ Poltava State Agrarian Academy, Poltava, Ukraine
}

Article info

Received 08.09.2020

Received in revised form 14.10.2020

Accepted 18.10.2020

Poltava State Agrarian Academy, Skovorody st., 1/3 Poltava, 36003, Ukraine. Tel.:+38-050-183-78-78. E-mail:evstva@ukr.net

\begin{abstract}
Yevstafieva, V. O., Melnychuk, V. V., Kanivets, N. S., Dmitrenko, N. I., Karysheva, L. P., \& Filonenko, S. V. (2020). Features of exogenous development of Trichuris globulosa (Nematoda, Trichuridae). Biosystems Diversity, 28(4), 337-342. doi:10.15421/012042
\end{abstract}

Parasitic nematodes of the genus Trichuris Röderer, 1761 are hematophagous helminths, capable of parasitizing many different hosts including humans. The domestic and wild ruminants are hosts of several Trichuris species, with Trichuris globulo$s a$ (Linstow, 1901) one of the most prevalent parasites found in cattle. The exogenous stages of the helminth's life cycle develop in the outer environment, and their activity and survival depend on the abiotic factors. Thus the aim of the work was to determine the influence of temperature on the rate and success of development of infectious eggs of $T$. globulosa in laboratory culture considering their morphological and metric changes. The results of experimental studies showed that the embryogenesis of T. globulosa eggs, cultured in laboratory conditions and obtained from gonads of female nematodes, occurs in six stages regardless of the temperature regime. At the same time, the rate of transition from one stage to another, the term for the formation of infectious eggs and their viability directly depends on the temperature of the external environment. At the optimal temperature for the development of $T$. globulosa eggs, $25^{\circ} \mathrm{C}, 76.3 \%$ of eggs reached the mobile larva stage. A decrease in temperature to $20^{\circ} \mathrm{C}$ and an increase to $30^{\circ} \mathrm{C}$ led to an increase in the egg mortality of up to $26 \%$ and $32 \%$, respectively, and the viability of eggs decreased. Under such temperature conditions, $74 \%$ and $68 \%$ of eggs of Trichuris reached the mobile larva stage. With an increase in the culture temperature, the time of embryogenesis decreased and amounted to 56 days at $20^{\circ} \mathrm{C}, 48$ days at $25^{\circ} \mathrm{C}$, and 32 days at $30^{\circ} \mathrm{C}$. Depending on the temperature regime, the zygote stage lasted from the release of eggs from the gonads of female nematodes to 12 days, the stage of blastomere formation from 4 to 12 days, the stage of the beanshaped embryo from 8 to 24 days, the stage of the tadpole embryo from 16 to 36 days, the stage of larval formation lasted from 16 to 48 days, the stage of mobile larva from days 20 to 56. The formation of the infectious $T$. globulosa egg from a noninfectious one is shown in an experiment to include the metric changes confirmed by metric indicators. Mature eggs with a mobile larva are shorter and wider, with shorter and narrower plugs and a thinner shell than eggs at the zygote stage. The obtained research results on the influence of temperature on the exogenous development of Trichuris globulosa will make it possible to predict the epizootic situation of trichurosis in animal husbandry, as well as take timely measures to arrest the embryonic stages of nematode development in the external environment.

Keywords: trichurosis; helminth egg; embryogenesis; temperature factor; metric indicators.

\section{Introduction}

Gastrointestinal nematodes cause common and very important from an economic point of view diseases of both domestic and wild animals around the world (Little, 2011; van der Voort et al., 2013; Ananta et al., 2014; Marskole et al., 2016; Susana et al., 2019). Among them, the most significant are zoonotic helminthiases which affect humans by the same stages of the pathogen that live in the animal bodies (Bawm \& Htun, 2015; Boyko \& Brygadyrenko, 2017, 2019, 2020). Such dangerous parasites include nematodes of the genus Trichuris Röderer, 1761, hematophagous helminths which have a significant distribution and species diversity (Ghai et al., 2014; Susana et al., 2019). Most of them are considered specific for certain taxonomic host groups (Callejón et al., 2015). Trichurosis of cattle is recorded everywhere (Gul \& Tak, 2016; Gunathilaka et al., 2018; Regea, 2019; Winarso et al., 2019). Trichuris globulosa Linstow, 1901 is one of the most common species of Trichuris that parasitize cattle (Keyyu et al., 2003; Pfukenyi \& Mukaratirwa, 2013). This pathogenic species is found in ruminants of the Azores Islands, Great Britain, Cyprus, Turkey, France, Germany, Italian, Poland, Spain, Bhutan, Nigeria, where the incidence in cattle varies from $0.09 \%$ to $14.5 \%$ (Jimenez et al., 2010; Tshering \& Dorji, 2013; De Jong et al., 2014; Odeniran et al., 2016; Susana et al., 2019).

This prevalence, according to researchers, is associated with the biological characteristics of parasites. Moreover, the most resistant to unfa- vourable factors is the exogenous stage of development, namely the Trichuris eggs (Pramasudha et al., 2015). Thus, the egg shell is multi-layered, provides mechanical protection, and also is resistant to chemicals. As a consequence, mature eggs of Trichuris can remain viable in the soil for a long time, which ensures the wide geographical distribution of the parasite (Roepstorff \& Murrell, 1997; Anvari-Tafti et al., 2013; Tudor, 2015). At the same time, the survival of nematode eggs depends on several factors such as climatic conditions, vegetation cover, seasonal air temperatures, fluctuations of soil moisture, and exposure to sunlight (Storey \& Phillips, 1985; Pecson et al., 2007; Maya et al., 2010). Adaptation to a parasitic lifestyle is accompanied by the appearance of special adaptations in helminths and their biological cycle to preserve the species. It is carried out, in most cases, in the external environment, to which the exogenous stages of parasite development adapt by the emergence of resistance to the effects of various environmental factors (Blaxter \& Koutsovoulos, 2015; Boyko et al., 2016; Al-Albudi \& Mosaab, 2017). Hence, helminth eggs whose embryonic development occurs in the external environment are more resistant to unfavourable factors than eggs that are already infectious in the external environment and partly develop in the body of the host. The resistance to the effects of environmental factors is extremely necessary for all exogenous development stages, since they undergo embryogenesis outside the host organism, and they also wait for rather a long term before entering the body of a new host (Knoop, 2012; Fataliev, 2013; Stroehlein et al., 2017; Charlier et al., 2018). 
A number of researchers have studied the features of embryonic development in nematodes of the genus Trichuris obtained from pigs, dogs, domestic and wild ruminants, and humans, from the stage of a fertilized egg containing an embryonic disc to the formation of an infectious egg. Their data show that for each individual species, the terms of egg development in the external environment, viability, stages of development and optimal conditions are quite different (Skriabyn et al., 1957; Fataliev, 2013; Yevstafieva et al., 2016; Yevstafieva et al., 2019). Therefore, it is very important to know the influence of changes in the external conditions surrounding the host on the biological characteristics of the exogenous stages of development of parasites, since seasonal changes in natural conditions lead to the parasites' adaptive responses so that the maximum number of eggs would become infectious to the host.

The aim of the present work is to establish the influence of temperature on the development and formation of infectious eggs of $T$. globulosa taking into account their morphological and metric changes.

\section{Materials and methods}

The nematodes were collected in the complete helminthological dissection of the large intestine obtained from young cattle (Skriabyn, 1928). The species of Trichuris was identified using a key (Skrjabin et al., 1957). In order to study the biological characteristics of parasitic T. globulosa nematodes in laboratory conditions, eggs were isolated from the gonads of female Trichuris.

Each separately obtained egg culture was placed in a Petri dish and cultivated in a thermostat at different temperatures $\left(20,25,30^{\circ} \mathrm{C}\right)$ until the formation of a mobile larva in egg. In total, three Petri dishes with cultures of Trichuris eggs were prepared. They were examined every four days, 100 eggs were chosen in each culture and their level of development was rated according to the following stages: zygote, blastomere formation, bean-shaped embryo, tadpole-shaped embryo, larva and mobile larva formation. Dead eggs and eggs that stopped developing were also counted.

The metric parameters of $T$. globulosa eggs (length and width of egg; length and width of egg plug; eggshell thickness) during cultivation were studied using the ImageJ for Windows ${ }^{\mathbb{B}}$ software (version 2.00) in interactive mode with a $\times 10, \times 40, \times 100$ objective and a $\times 10$ photo eyepiece. To calibrate the image analyzer, ruled scale of ocular micrometer was adjusted to the scale of stage micrometer included in MikroMed microscope kit. Microphotography was performed using a digital camera attached to a MikroMed 5 Mpix microscope (China).

Standard deviation (SD) and average values (x) were calculated. Significance of difference between average values in the studied T. globulosa eggs was established using one-way analysis of variance and F-test for $95 \%$ confidence level.

\section{Results}

In the embryogenesis of T. globulosa nematodes obtained from cattle, six stages can be distinguished: zygote, blastomere formation, beanshaped embryo, tadpole-shaped embryo, larva and mobile larva formation. The last stage is infectious to animals. The zygote stage corresponded to the fertilized egg, in which its contents were evenly distributed (Fig. 1a).

Subsequently, blastomere formation was noted in the egg (Fig. 1b). At this stage, the presence of larger blastomeres was first noted, which became smaller due to multiplying. Further development was accompanied by a change in the general shape of the embryo, which resembled the shape of a bean. The embryo thickened to the middle and detached from the membrane at egg poles (Fig. 1c). The next stage was characterized by the formation of a tadpole embryo which gradually, unevenly elongated (Fig. 1d). In the next developmental stage, a larva formed with a body filled with a granular mass (Fig. 1e). At this stage, the larva remained motionless. The larva then greatly grew in length, its body became denser and lighter (Fig. 1f). The larva actively moved inside the vitelline membrane. The exogenous development of $T$. globulosa eggs, namely, the rate of transition from one stage to another, duration of the formation of infectious eggs and their viability, directly depended on the temperature of the external environment. The higher the cultivation temperature was, the shorter the stages of development were, and the faster the formation of infectious larvae occurred. At the same time, the number of viable eggs formed in nematodes did not depend on the rate of embryogenesis. At a temperature of $20^{\circ} \mathrm{C}$, the formation of the maximum number of infectious larvae $(74.0 \pm 2.6 \%)$ occurred in 56 days. The death of Trichuris eggs was at the level of $26.0 \pm 2.6 \%$ (Table 1 ).

The zygote stage lasted from the isolation of eggs from the gonads of female Trichuris to 12 days, with their ratio gradually decreasing from $100 \%$ to $50.0 \pm 1.0 \%$. Until day 20 , the number of eggs at this stage decreased to $6.0 \pm 3.6 \%$, and on day 24 , no eggs with zygotes were detected. The stage of blastomere formation lasted from the 4th to 12th days of cultivation, when the largest number of such eggs formed, from $13.0 \pm$ $2.0 \%$ to $26.3 \pm 2.0 \%$. From the 20 th to 32 nd days the number of eggs at this stage decreased to $3.3 \pm 1.5 \%$. The formation of the maximum number of eggs $(53.3 \pm 3.0 \%)$ with the stage of bean-like embryo lasted from the 12th to 24th days. Subsequently, their number decreased and the minimum ratios $(9.7 \pm 2.5 \%)$ were recorded on day 44 of cultivation. The stage of formation of a tadpole embryo began from day 24 , where $11.0 \pm$ $1.0 \%$ of eggs were found at this stage. The maximum number of such eggs formed on the 36th day of cultivation ( $40.7 \pm 1.1 \%$ ), and by the 48 th day only $17.0 \pm 2.0 \%$ of the eggs contained a tadpole embryo. From the 32nd day of cultivation, the formation of larvae was recorded in $4.0 \pm$ $1.0 \%$ of the eggs, and from the 44th day, they became mobile and the eggs became infectious.

\section{Table 1}

Periods of exogenous development of eggs and their viability

in laboratory conditions were assessed at a temperature of $20^{\circ} \mathrm{C}(\mathrm{x} \pm \mathrm{SD}, \mathrm{n}=3)$

\begin{tabular}{|c|c|c|c|c|c|c|c|}
\hline \multirow{2}{*}{$\begin{array}{c}\text { Duration } \\
\text { of cultivation, day }\end{array}$} & \multicolumn{7}{|c|}{ Stage of development, $\%$} \\
\hline & zygote & blastomere formation & bean-like embryo & tadpole embryo & larva formation & mobile larva & egg death \\
\hline before cultivation & 100 & - & - & - & - & - & - \\
\hline 4 & $87.0 \pm 2.0$ & $13.0 \pm 2.0$ & - & - & - & - & - \\
\hline 8 & $62.3 \pm 2.3$ & $18.7 \pm 3.0$ & - & - & - & - & $19.0 \pm 2.0$ \\
\hline 12 & $50.0 \pm 1.0$ & $26.3 \pm 2.0$ & $2.0 \pm 1.0$ & - & - & - & $21.7 \pm 1.1$ \\
\hline 16 & $23.7 \pm 2.5$ & $23.3 \pm 1.5$ & $29.3 \pm 0.5$ & - & - & - & $23.7 \pm 1.5$ \\
\hline 20 & $6.0 \pm 3.6$ & $17.0 \pm 2.0$ & $52.7 \pm 1.1$ & - & - & - & $24.3 \pm 2.5$ \\
\hline 24 & - & $9.7 \pm 0.5$ & $53.3 \pm 3.0$ & $11.0 \pm 1.0$ & - & - & $26.0 \pm 2.6$ \\
\hline 28 & - & $6.7 \pm 0.5$ & $38.3 \pm 1.1$ & $29.0 \pm 3.6$ & - & - & $26.0 \pm 2.6$ \\
\hline 32 & - & $3.3 \pm 1.5$ & $30.3 \pm 0.5$ & $36.3 \pm 2.0$ & $4.0 \pm 1.0$ & - & $26.0 \pm 2.6$ \\
\hline 36 & - & - & $24.0 \pm 2.0$ & $40.7 \pm 1.1$ & $9.3 \pm 1.5$ & - & $26.0 \pm 2.6$ \\
\hline 40 & - & - & $19.0 \pm 1.0$ & $35.7 \pm 3.2$ & $19.3 \pm 1.5$ & - & $26.0 \pm 2.6$ \\
\hline 44 & - & - & $9.7 \pm 2.5$ & $34.0 \pm 1.0$ & $24.3 \pm 0.5$ & $6.0 \pm 1.0$ & $26.0 \pm 2.6$ \\
\hline 48 & - & - & - & $17.0 \pm 2.0$ & $31.3 \pm 2.0$ & $25.7 \pm 1.5$ & $26.0 \pm 2.6$ \\
\hline 52 & - & - & - & - & $15.0 \pm 2.0$ & $59.0 \pm 1.0$ & $26.0 \pm 2.6$ \\
\hline 56 & - & - & - & - & - & $74.0 \pm 2.6$ & $26.0 \pm 2.6$ \\
\hline
\end{tabular}

Note: they were examined every four days, 100 eggs were chosen in each culture and their level of development was rated according to the following stages: zygote, blastomere formation, bean-shaped embryo, tadpole-shaped embryo, larva and mobile larva formation, egg death. 

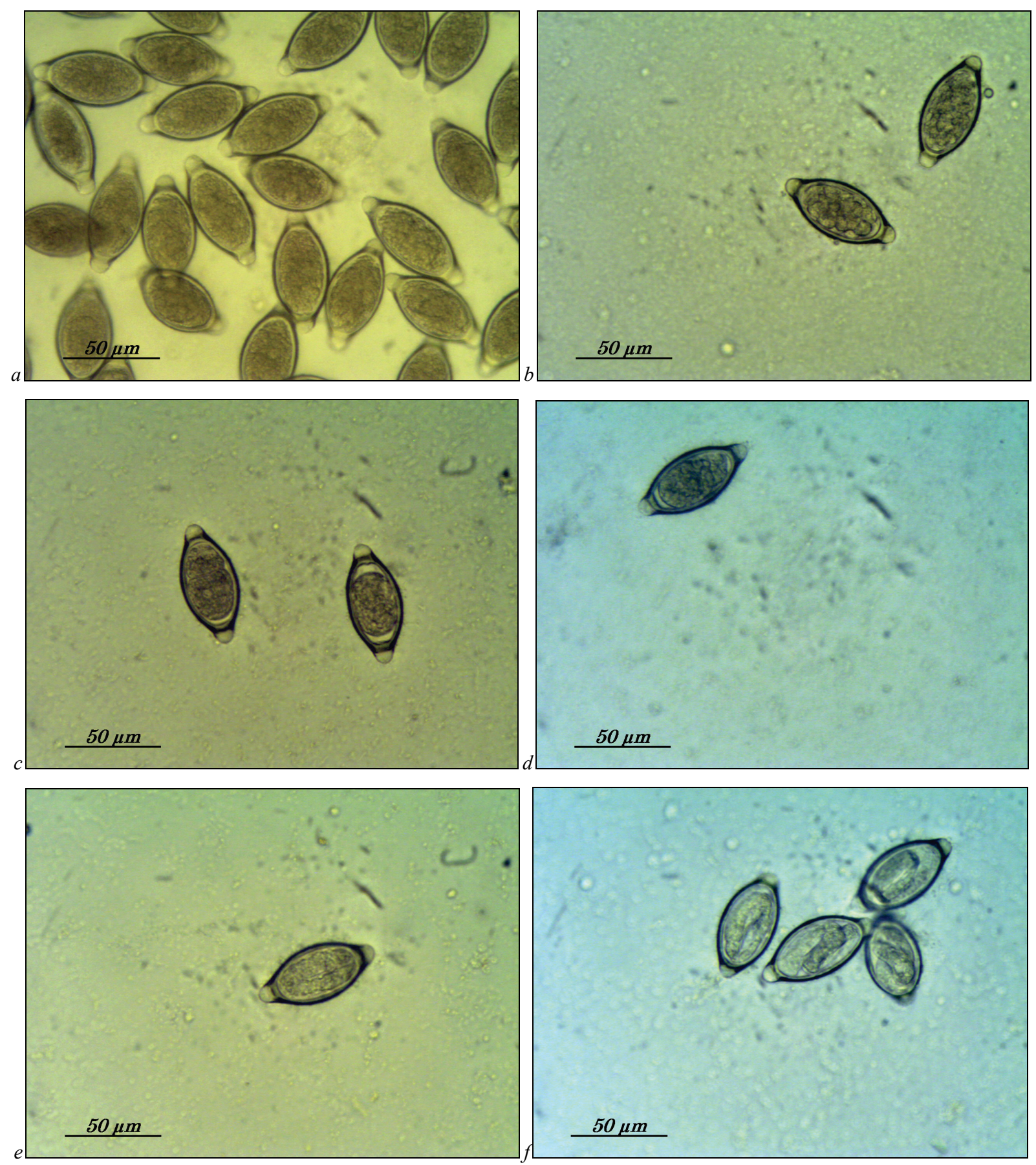

Fig. 1. Stages of Trichuris globulos $a$ embryogenesis: $a$-zygote; $b$-blastomere formation; $c$ - bean-shaped embryo; $d$-tadpole-shaped embryo; $e$-larva formation; $f$-mobile larva formation

The temperature regime at $25^{\circ} \mathrm{C}$ was found to be the most favourable for the exogenous development of $T$. globulosa. That cultivation temperature was accompanied by formation of the maximum ratio of infectious eggs, $76.3 \pm 1.5 \%$, and their death was $23.7 \pm 1.5 \%$. The embryogenesis period was shorter than at $20^{\circ} \mathrm{C}$ and amounted to 48 days (Table 2).

The embryogenesis proceeded faster, thence the timing of each stage was also shorter. The zygote stage lasted from days 1 to 8 , when more than $50 \%$ of the eggs were still at that stage. The stage of blastomere formation lasted from days 4 to 12 , and the amount of egg formation increased from $25.3 \pm 3.0 \%$ to $50.7 \pm 3.7 \%$. From the 16 th day of cultivation, the ratio of eggs with blastomeres gradually decreased to $5.0 \pm 3.0 \%$, and from the 28th day, such eggs were not recorded. The stage of beanlike embryo lasted from the 12th day $(15.3 \pm 4.0 \%)$ to the 20th day $(49.3 \pm$ $2.0 \%$ ). A small number of eggs at that stage of development (from $41.0 \pm$ $2.0 \%$ to $4.3 \pm 3.5 \%$ ) were detected up to the 36 th day. The stage of the tadpole-shaped embryo was found on the 20th day, when $18.6 \pm 2.0 \%$ of eggs were found. Subsequently, by the 28th day of cultivation, the maxi- mum ratio of such eggs formed, $40.0 \pm 1.0 \%$, and by the 40 th day there were $3.7 \pm 2.0 \%$ of such eggs. The stage of larva formation lasted from the 28th to the 40th day, when the maximum ratio of eggs was $44.3 \pm$ $3.0 \%$. On day 44 , only $10.7 \pm 1.5 \%$ of the eggs contained an immobile larva. The formation of infectious eggs was recorded from the 36th to the 48th day, and their ratio gradually increased from $5.7 \pm 3.5 \%$ to $76.3 \pm 1.5 \%$.

At a temperature of $30^{\circ} \mathrm{C}$, the period of development of T. globulosa eggs was the shortest (up to 32 days), but at the same time their survival rate was the lowest and amounted to $68.0 \pm 2.6 \%$. The ratio of egg death during embryogenesis was the highest, $32.0 \pm 2.6 \%$ (Table 3 ).

The zygote stage lasted from the moment of isolation of eggs from the gonads of female Trichuris and up to day 4, when the egg ratio gradually decreased from $100 \%$ to $25.7 \pm 2.5 \%$. During days $8-12$, their ratio was minimal and ranged from $19.0 \pm 1.0 \%$ to $7.0 \pm 2.0 \%$. The stage of blastomere formation lasted from days 4 to 8 of cultivation, when the largest ratio of eggs formed, from $74.3 \pm 2.5 \%$ to $44.3 \pm 2.5 \%$. On the 16th day of egg cultivation, only $9.7 \pm 3.5 \%$ remained at that stage. 
Table 2

Periods of exogenous development of eggs and their viability in laboratory conditions were assessed at a temperature of $25^{\circ} \mathrm{C}(\mathrm{x} \pm \mathrm{SD}, \mathrm{n}=3)$

\begin{tabular}{|c|c|c|c|c|c|c|c|}
\hline \multirow{2}{*}{$\begin{array}{c}\text { Duration } \\
\text { of cultivation, day }\end{array}$} & \multicolumn{7}{|c|}{ Stage of development, \% } \\
\hline & zygote & blastomere formation & bean-like embryo & tadpole embryo & larva formation & mobile larva & egg death \\
\hline before cultivation & 100 & - & - & - & - & - & - \\
\hline 4 & $74.7 \pm 3.0$ & $25.3 \pm 3.0$ & - & - & - & - & - \\
\hline 8 & $42.3 \pm 1.5$ & $44.3 \pm 3.5$ & - & - & - & - & $13.3 \pm 2.0$ \\
\hline 12 & $17.3 \pm 2.0$ & $50.7 \pm 3.7$ & $15.3 \pm 4.0$ & - & - & - & $16.7 \pm 0.5$ \\
\hline 16 & $6.3 \pm 2.5$ & $28.0 \pm 1.7$ & $47.3 \pm 2.0$ & - & - & - & $18.3 \pm 1.5$ \\
\hline 20 & - & $8.3 \pm 2.5$ & $49.3 \pm 2.0$ & $18.7 \pm 2.0$ & - & - & $23.7 \pm 1.5$ \\
\hline 24 & - & $5.0 \pm 3.0$ & $41.0 \pm 2.0$ & $30.3 \pm 2.5$ & - & - & $23.7 \pm 1.5$ \\
\hline 28 & - & - & $26.0 \pm 1.7$ & $40.0 \pm 1.0$ & $10.3 \pm 1.5$ & - & $23.7 \pm 1.5$ \\
\hline 32 & - & - & $20.3 \pm 2.5$ & $38.3 \pm 0.5$ & $17.7 \pm 1.5$ & - & $23.7 \pm 1.5$ \\
\hline 36 & - & - & $4.3 \pm 3.5$ & $32.7 \pm 2.0$ & $33.7 \pm 1.1$ & $5.7 \pm 3.5$ & $23.7 \pm 1.5$ \\
\hline 40 & - & - & - & $3.7 \pm 2.0$ & $44.3 \pm 3.0$ & $28.3 \pm 0.5$ & $23.7 \pm 1.5$ \\
\hline 44 & - & - & - & - & $10.7 \pm 1.5$ & $65.7 \pm 1.5$ & $23.7 \pm 1.5$ \\
\hline 48 & - & - & - & - & - & $76.3 \pm 1.5$ & $23.7 \pm 1.5$ \\
\hline
\end{tabular}

Note: see Table 1 .

Table 3

Periods of exogenous development of eggs and their viability in laboratory conditions were assessed at a temperature of $30{ }^{\circ} \mathrm{C}(\mathrm{x} \pm \mathrm{SD}, \mathrm{n}=3)$

\begin{tabular}{|c|c|c|c|c|c|c|c|}
\hline \multirow{2}{*}{$\begin{array}{c}\text { Duration } \\
\text { of cultivation, day }\end{array}$} & \multicolumn{7}{|c|}{ Stage of development, \% } \\
\hline & zygote & blastomere formation & bean-like embryo & tadpole embryo & larva formation & mobile larva & egg death \\
\hline before cultivation & 100 & - & - & - & - & - & - \\
\hline 4 & $25.7 \pm 2.5$ & $74.3 \pm 2.5$ & - & - & - & - & - \\
\hline 8 & $19.0 \pm 1.0$ & $44.3 \pm 2.5$ & $20.7 \pm 1.5$ & - & - & - & $16.0 \pm 2.0$ \\
\hline 12 & $7.0 \pm 2.0$ & $26.0 \pm 2.6$ & $45.7 \pm 3.2$ & - & - & - & $21.3 \pm 2.5$ \\
\hline 16 & - & $9.7 \pm 3.5$ & $28.3 \pm 1.1$ & $30.0 \pm 3.0$ & $7.7 \pm 3.5$ & - & $24.3 \pm 3.0$ \\
\hline 20 & - & - & $3.0 \pm 1.7$ & $40.3 \pm 4.5$ & $22.0 \pm 1.0$ & 2.7 & $32.0 \pm 2.6$ \\
\hline 24 & - & - & - & $5.3 \pm 2.5$ & $39.0 \pm 2.6$ & $23.7 \pm 2.8$ & $32.0 \pm 2.6$ \\
\hline 28 & - & - & - & - & $7.3 \pm 3.0$ & $60.7 \pm 5.6$ & $32.0 \pm 2.6$ \\
\hline 32 & - & - & - & - & - & $68.0 \pm 2.6$ & $32.0 \pm 2.6$ \\
\hline
\end{tabular}

Note: see Table 1.

The stage of the bean-like embryo with the formation of the maximum number of eggs $(45.7 \pm 3.2 \%)$ lasted from days 8 to 12 . Subsequently, their number decreased and the minimum values $(3.0 \pm 1.7 \%)$ were recorded on the 20th day of cultivation. The formation of a tadpole embryo in eggs was recorded from the 16th day $(30.0 \pm 3.0 \%)$, and their maximum number was detected on the 20th day of cultivation ( $40.3 \pm$ $4.5 \%$ ). From the 16th day of cultivation, $7.7 \pm 3.5 \%$ of eggs were recorded at the stage of larval formation. On the 24th day, their maximum number was observed, $39.0 \pm 2.6 \%$. Mobile larvae were found in eggs starting from the 20th day $(2.7 \%)$, their maximum ratio formed up to the 32 nd day $(68.0 \pm$ $2.6 \%$ ). At all temperature regimes, the death of eggs during embryogenesis was mainly accompanied by an increase in the porosity of the egg shell, as a result of which the embryo became aerated and air bubbles formed in the embryo (Fig. 2). Subsequently, the eggs stopped developing and gradually lysed.

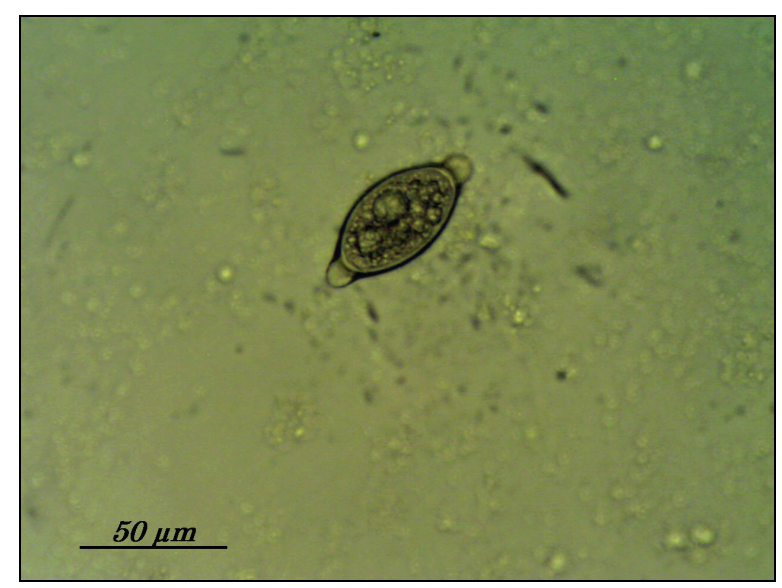

Fig. 2. Features of Trichuris globulosa of egg death in embryogenesis

The growth and development of $T$. globulosa eggs during embryogenesis were accompanied by changing metric parameters. Thus, in infectious eggs, a significant decrease in length by $3.2 \%(62.8 \pm 1.6 \mu \mathrm{m}, \mathrm{P}<$ 0.01 , Fig. 3a) and an increase in width by $7.7 \%(30.0 \pm 0.7 \mu \mathrm{m}, \mathrm{P}<0.001$,
Fig. 3b) were revealed in eggs at the zygote stage $(64.9 \pm 1.6$ and $27.7 \pm$ $0.8 \mu \mathrm{m}$, respectively). Also, in eggs of Trichuris at the stage of developing mobile larva, the egg plug length decreased by $19.3 \%(7.1 \pm 0.7 \mu \mathrm{m}, \mathrm{P}<$ 0.001 , Fig. $3 \mathrm{c})$ and the egg plug width decreased by $15.9 \%(9.0 \pm 0.6 \mu \mathrm{m}$, $\mathrm{P}<0.001$, Fig. $3 \mathrm{~d})$, the shell thickness also reduced by $31.6 \%(1.3 \pm$ $0.1 \mu \mathrm{m}, \mathrm{P}<0.001$, Fig. 3e).

Thus, the exogenous development of $T$. globulosa parasitic nematodes obtained from cattle is accompanied by certain stages, each of which is necessary for the formation of an infectious agent capable of infecting a susceptible host. The timing of development and the degree of survival of the parasite depends on the temperature factor.

\section{Discussion}

According to scientific studies, Trichuris infections are common, and some species are also pathogens of dangerous zooanthroponotic diseases of animals and humans (Bawm \& Htun, 2015; Boyko \& Brygadyrenko, 2016, 2019). Trichuris globulosa is recorded in ruminants in many countries of the world, where the incidence can be $14.5 \%$ (De Jong et al., 2014; Odeniran et al., 2016; Susana et al., 2019). Temperature, relative humidity, and $\mathrm{pH}$ of the environment are the main abiotic factors affecting the survival of parasites in the environment, and as a consequence the degree of their prevalence. This is because nematodes of the genus Trichuris are characterized by a host-soil-host cycle. At the same time, they need an exogenous period for the maturation of infectious eggs, which are the most resistant to adverse environmental factors (Anvari-Tafti et al., 2013; Pramasudha et al., 2015; Tudor, 2015).

We found that the exogenous development of $T$. globulosa isolated from cattle depends on temperature. Moreover, with an increase in the temperature regime, the development of invasive eggs occurs faster. A lower temperature slows down the embryogenesis process. The optimal temperature for the formation of the largest number of viable mature eggs with a mobile larva $(76.3 \pm 1.5 \%)$ was $25^{\circ} \mathrm{C}$. At a temperature of $20^{\circ} \mathrm{C}$, fewer infectious eggs formed $(74.0 \pm 2.6 \%)$. An increase in temperature to $30^{\circ} \mathrm{C}$ led to the death of a larger number of eggs, and the ratio of eggs that became infectious was $68.0 \pm 2.6 \%$. The data obtained confirm the studies which show that the life of organisms, including parasitic ones, is deter- 
mined by temperature more than by any factor of the external environment. This is due to the fact that all organisms are built of chemical components and all life processes occur on the basis of chemical reactions, subject to the laws of thermodynamics.
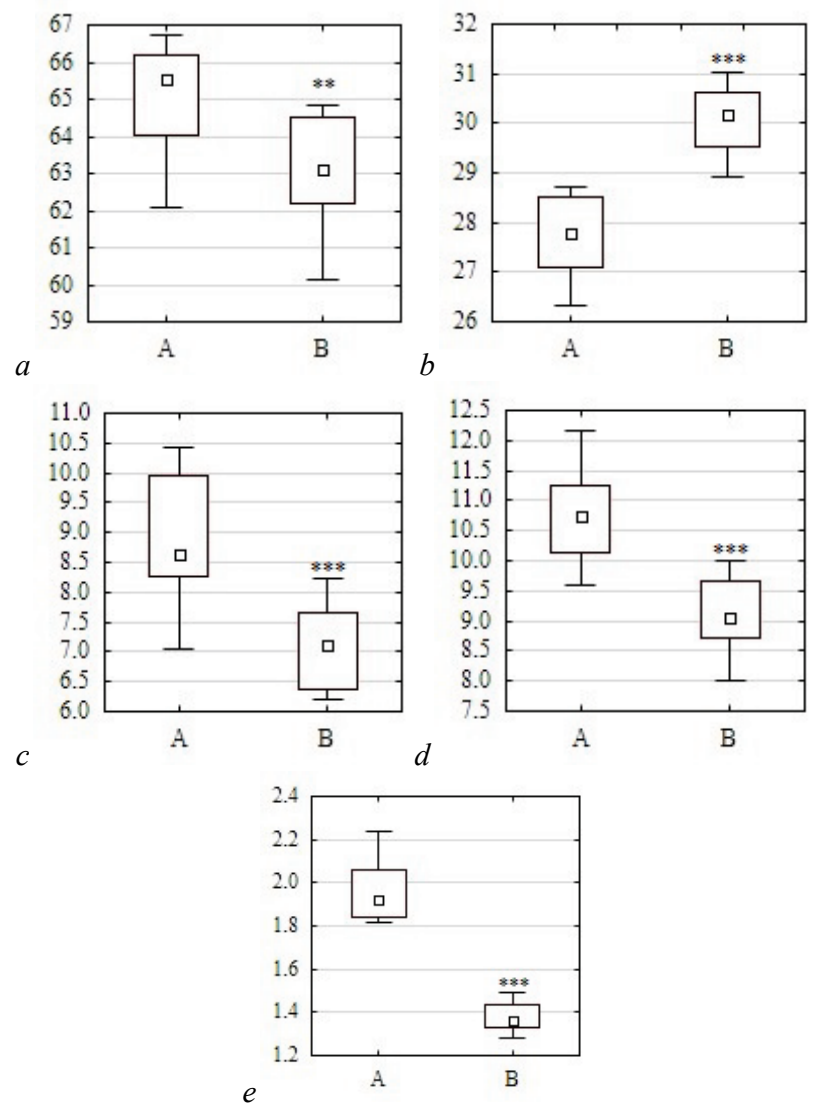

Fig. 3. The indicators of growth and development of Trichuris globulosa eggs in laboratory conditions at a temperature of $25^{\circ} \mathrm{C}: a$ - egg length,

$b$-egg width, $c$-egg plug length, $d$ - egg plug width, $e$ - eggshell thickness $(\mu \mathrm{m}) ; A$-zygote stage, $B$ - stage of mobile larva formation; $* *-\mathrm{P}<0.01, * * *-\mathrm{P}<0.001$ compared to values of egg parameters at zygote stage; the small square in the centre corresponds to the median, the lower and upper borders of the large rectangular correspond to the first and the third quartiles, respectively, vertical line segments, directed up and down from the rectangular, correspond to minimum and maximum values $(\mathrm{n}=10)$

Temperature affects not only the rate of chemical reactions, but is also a prerequisite for the structural rearrangement of proteins, phase displacement of fats, and changes in the structure of water. For all organisms there is a vital temperature zone, within which their vital activity is carried out and fits into certain boundaries. The lower limit of the active life of parasitic organisms is limited, first of all, by drop-liquid water, the constant flow of which is the processes of assimilation and dissimilation. Therefore, the crystallization of water serves as a critical threshold for their life. The upper temperature limit is characterized by thermal coagulation of proteins. The eggs of parasites are more resistant to low temperatures than to high ones, due to the many direct and indirect adaptations developed in the process of evolution. That is, low temperatures slow down metabolic processes inside the egg and the development of the larva, but the viability of the egg is preserved (El-Hamouri et al., 1994; Pecson et al., 2007).

Our studies have established that temperature also affects the rate of embryogenesis of $T$. globulosa. With an increase in temperature, the rate of development of Trichuris eggs of increases. The shortest term of exogenous development was observed at a cultivation temperature of $30^{\circ} \mathrm{C}$, the infectious larvae formed on the $32 \mathrm{nd}$ day. At a temperature of $25^{\circ} \mathrm{C}$, the development of eggs slightly slowed down and amounted to 48 days. The longest exogenous development of $T$. globulosa was recorded at a temperature of $20^{\circ} \mathrm{C}$, the period of formation of infectious eggs was 56 days. Similar data are described by the authors who show that the time of development of $T$. trichiura eggs decreases with increasing tempera- ture. Moreover, the upper limit of the egg survival temperature is at 37$38^{\circ} \mathrm{C}$ (Beer, 1976; Bundy \& Cooper, 1989; Pullan et al., 2011). In study of the embryonic development of T. skrjabini isolated from sheep, it was found that at $27{ }^{\circ} \mathrm{C}$ eggs reached the infectious stage at 51 days, and their viability was $80 \%$ (Yevstafieva et al., 2018).

In the experimental cultivation of eggs of parasitic $T$. globulosa isolated from cattle, we identified 6 morphologically different stages of embryogenesis, namely zygote, formation of blastomeres, bean-shaped embryo, tadpole-shaped embryo, formation of larva and mobile larva. The duration of each stage was different depending on the temperature regime. The higher the temperature, the less time it took for the transition from one stage of egg development to another. Thus, the zygote stage lasted from the moment the eggs were isolated from the gonads of female Trichuris and up to 4 days (at a temperature of $30^{\circ} \mathrm{C}$ ), to 8 days $\left(25^{\circ} \mathrm{C}\right)$, to 12 days $\left(20^{\circ} \mathrm{C}\right)$. The maximum formation of blastomeres occurred depending on temperature $\left(30,25,20^{\circ} \mathrm{C}\right)$ at $4-8,4-12$, and $4-16$ days, and the stage of the bean-like embryo at 8-12, 12-20 and 12-24 days, respectively.

The stage of the tadpole-shaped embryo was the shortest at $30^{\circ} \mathrm{C}$ and lasted from days 16-20 of cultivation. At temperatures of 25 and $20^{\circ} \mathrm{C}$, this stage began at a later date than at a temperature of $30^{\circ} \mathrm{C}$, and lasted, respectively, from days 20 to 28 and from days 24 to 36 of cultivation. The same tendency was noted in the timing of the stages of larval and mobile larva formation. At $30^{\circ} \mathrm{C}$, these stages lasted from days 16-24 and $20-32$, respectively. At a temperature of $25^{\circ} \mathrm{C}$, these stages of development of Trichuris eggs lasted from days $28-40$ and $36-48$, and at a temperature of $20^{\circ} \mathrm{C}$, from days $32-48$ and $44-56$, respectively. The same data on certain stages in the exogenous development of Trichuris were already noted in our previous works, where the peculiarities of T. suis and T. skrjabini embryogenesis were studied. Moreover, the duration of each identified stage and the degree of egg survival in the process of their development differed significantly for each species (Yevstafieva et al., 2015, 2018).

We also established the metric changes in T. globulosa eggs during embryogenesis. The formation of a mobile larva was accompanied by a decrease in egg length (by $3.2 \%, \mathrm{P}<0.01$ ), the length and width of the egg plug (by $19.3 \%$ and $15.9 \%, \mathrm{P}<0.001$ ), an increase in the egg width (by $7.7 \%, \mathrm{P}<0.001$ ), and a decrease in the eggshell thickness (by $31.6 \%, \mathrm{P}<$ 0.001 ) in comparison with similar indicators in eggs at the zygote stage. Such changes may indicate that the stages of development differ not only in morphological features, but also in metric indicators.

The obtained results of study on the influence of temperature on the exogenous development of $T$. globulosa will make it possible to predict the epizootic situation of trichurosis in animal husbandry, as well as to take timely measures against the embryonic nematode development in the external environment. The environment contaminated with parasite eggs represents the main risk to human and animal health in the case of this disease. Preventing initial contamination and studying the factors that cause egg death in the environment are an important way to avoid contamination of humans and animals.

\section{Conclusion}

It is shown that the exogenous development of $T$. globulosa Linstow, 1901 parasitic nematodes in laboratory conditions occurs in 6 stages: zygote, blastomere formation, bean-shaped embryo, tadpole-shaped embryo, larva and mobile larva formation. The duration of embryogenesis, the term for each stage of development, and the degree of egg survival and the ratio of infectious eggs depend on the temperature factor. The cultivation temperature of $25^{\circ} \mathrm{C}$ turned out to be optimal for the formation of the largest number of viable mature eggs with a mobile larva $(76.3 \pm 1.5 \%)$. Temperatures at the level of 20 and $30^{\circ} \mathrm{C}$ led to a decrease in the viability of eggs during embryogenesis, and the proportion of formed infectious eggs did not exceed $74.0 \pm 2.6 \%$ and $68.0 \pm 2.6 \%$. The development time of T. globulosa eggs gradually decreased with increasing temperature. At $30^{\circ} \mathrm{C}$, embryogenesis was the shortest and amounted to 32 days. At $25^{\circ} \mathrm{C}$, the egg development period was longer, occurring in 48 days. At $20^{\circ} \mathrm{C}$, the formation of the maximum number of infectious eggs at the stage of mobile larvae lasted up to 56 days. Morphological changes in T. globulosa eggs were accompanied by significant metric changes. Eggs at the stage of mobile larva were shorter and wider, had shorter and narrower plugs, as well as a thinner shell than eggs at the zygote stage. 


\section{References}

Al-Albudi, M., \& Mosaab, O. (2017). Prevalence of gastrointestinal nematodes of farm animals by copro-culture. Russian Journal of Parasitology, 2, 168-174.

Ananta, S. M., Suharno, H. A., \& Matsubayashi, M. (2014). Survey on gastrointestinal parasites and detection of Cryptosporidium spp. on cattle in West Java, Indonesia. Asian Pacific Journal of Tropical Medicine, 7(3), 197-201.

Anvari-Tafti, M., Sazmand, A., Hekmatimoghaddam, S., \& Moobedi, I. (2013). Gastrointestinal helminths of camels (Camelus dromedarius) in center of Iran. Tropical Biomedicine, 30(1), 56-61.

Bawm, S., \& Htun, L. L. (2015). Parasitic zoonoses in livestock and domestic animals of Myanmar and neighbouring countries. Asian Journal of Animal and Veterinary Advances, 10(11), 740-751

Beer, R. J. (1976). The relationship between Trichuris trichiura (Linnaeus 1758) of man and Trichuris suis (Schrank 1788) of the pig. Research in Veterinary Science, $20(1), 47-54$

Blaxter, M., \& Koutsovoulos, G. (2015). The evolution of parasitism in Nematoda Parasitology, 142(1), 26-39.

Boyko, A. A., \& Brygadyrenko, V. V. (2017). Changes in the viability of Strongyloides ransomi larvae (Nematoda, Rhabditida) under the influence of synthetic flavourings. Regulatory Mechanisms in Biosystems, 8(1), 36-40.

Boyko, O. O., \& Brygadyrenko, V. V. (2019). The impact of acids approved for use in foods on the vitality of Haemonchus contortus and Strongyloides papillosus (Nematoda) larvae. Helminthologia, 56(3), 202-210.

Boyko, O. O., \& Brygadyrenko, V. V. (2020). The impact of certain flavourings and preservatives on the survivability of eggs of Ascaris suum and Trichuris suis. Regulatory Mechanisms in Biosystems, 11(2), 344-348.

Bundy, D. A., \& Cooper, E. S. (1989). Trichuris and trichuriasis in humans. Advances in Parasitology, 28, 107-173.

Callejón, R., Gutiérrez-Avilés, L., Halajian, A., Zurita, A., de Rojas, M., \& Cutillas, C. (2015). Taxonomy and phylogeny of Trichuris globulosa Von Linstow, 1901 from camels. A review of Trichuris species parasitizing herbivorous. Infection, Genetics and Evolution, 34, 61-74.

Callejón, R., Robles, M., Panei, C. J., \& Cutillas, C. (2016). Molecular diversification of Trichuris spp. from Sigmodontinae (Cricetidae) rodents from Argentina based on mitochondrial DNA sequences. Parasitology Research, 115(8), 2933-2945.

Charlier, J., Thamsborg, S. M., Bartley, D. J., Skuce, P. J., Kenyon, F., Geurden, T., Hoste, H., Williams, A. R., Sotiraki, S., Höglund, J., Chartier, C., Geldhof, P., van Dijk, J., Rinaldi, L., Morgan, E. R., von Samson-Himmelstjerna, G., Vercruysse, J., \& Claerebout, E. (2018). Mind the gaps in research on the control of gastrointestinal nematodes of farmed ruminants and pigs. Transboundary and Emerging Diseases, 65(1), 217-234.

De Jong, Y., Verbeek, M., Michelsen, V., Bjørn, P., de P., Los, W., Steeman, F., Bailly, N., Basire, C., Chylarecki, P., Stloukal, E., Hagedorn, G., Wetzel, F. T., Glöckler, F., Kroupa, A., Korb, G., Hoffimann, A., Häuser, C., Kohlbecker, A. Müller, A., Güntsch, A., Stoev, P., \& Penev, L. (2014). Fauna Europaea - all European animal species on the web. Biodiversity Data Journal, 2, e4034.

El Hamouri, B., Khallayoune, K., Bouzoubaa, K., Rhallabi, N., \& Chalabi, M. (1994). High-rate algal pond performances in fecal coliforms and helminth egg removals. Water Research, 28, 171-174.

Fataliev, G. (2013). Influence of abiotic factors on the embryonal development of Trichocephalus myocastoris (Nematoda, Trichocephalidae) in Azerbaijan. Zoological Joumal, 92(12), 1475-1477.

Ghai, R. R., Simons, N. D., Chapman, C. A., Omeja, P. A., Davies, T. J., Ting, N., \& Goldberg, T. L. (2014). Hidden population structure and cross-species transmission of whipworms (Trichuris sp.) in humans and non-human primates in Uganda. PLoS Neglected Tropical Diseases, 8(10), e3256.

Gul, N., \& Tak, H. (2016). Prevalence of Trichuris spp. in small ruminants slaughtered in Srinagar District (J\&K). Journal of Parasitic Diseases, 40(3), 741-744.

Gunathilaka, N., Niroshana, D., Amarasinghe, D., \& Udayanga, L. (2018). Prevalence of gastrointestinal parasitic infections and assessment of deworming program among cattle and buffaloes in Gampaha District, Sri Lanka. BioMed Research International, 2018, 3048373.

Jiménez, A. E., Fernández, A., Alfaro, R., Dolz, G., Vargas, B., Epe, C., \& Schnieder, T. (2010). A cross-sectional survey of gastrointestinal parasites with dispersal stages in feces from Costa Rican dairy calves. Veterinary Parasitology, 173, 236-246.

Keyyu, J. D., Kassuku, A. A., Kyvsgaard, N. C., \& Willingham, A. L. (2003). Gastrointestinal nematodes in indigenous Zebu cattle under pastoral and nomadic management systems in the lower plain of the southern highlands of Tanzania. Veterinary Research Communications, 27(5), 371-380.

Knopp, S., Steinmann, P., Keiser, J., \& Utzinger, J. (2012). Nematode infections: Soil-transmitted helminths and Trichinella. Infectious Disease Clinics of North America, 26(2), 341-358.

Little, P. R., Hodge, A., Maeder, S. J., Wirtherle, N. C., Nicholas, D. R., Cox, G. G., \& Conder, G. A. (2011). Efficacy of a combined oral formulation of derquantel- abamectin against the adult and larval stages of nematodes in sheep, including anthelmintic-resistant strains. Veterinary Parasitology, 181, 180-193.

Marskole, P., Verma, Y., Dixit, A. K., \& Swamy, M. (2016). Prevalence and burden of gastrointestinal parasites in cattle and buffaloes in Jabalpur, India. Veterinary World, 9(11), 1214-1217.

Maya, C., Ortiz, M., \& Jiménez, B. (2010). Viability of Ascaris and other helminth genera non larval eggs in different conditions of temperature, lime $(\mathrm{pH})$ and humidity. Water Science and Technology, 62(11), 2616-2624.

Odeniran, P. O., Jegede, H. O., \& Adewoga, T. O. (2016). Prevalence and risk perception of adult-stage parasites in slaughtered food animals (cattle, sheep and goat) among local meat personnel in Ipata abattoir, Ilorin, Nigeria. Veterinary Medicine and Animal Sciences, 4, 1-6.

Pecson, B. M., Barrios, J. A., Jiménez, B. E., \& Nelson, K. L. (2007). The effects of temperature, $\mathrm{pH}$, and ammonia concentration on the inactivation of Ascaris eggs in sewage sludge. Water Research, 41(13), 2893-2902.

Pfukenyi, D. M., \& Mukaratirwa, S. (2013). A review of the epidemiology and control of gastrointestinal nematode infections in cattle in Zimbabwe. Onderstepoort Journal of Veterinary Research, 80(1), 612-624.

Pramasudha, A. A. R., Nyoman, A. S., \& Ida, B. M. O. (2015). The prevalence of Trichuris spp. in Bali cattle according to the layout geographic of Bali Province. Udayana Veterinary Bulletin, 7(2), 202-208.

Pullan, R. L., Gething, P. W., Smith, J. L., Mwandawiro, C. S., Sturrock, H. J., Gitonga, C. W., Hay, S. I., \& Brooker, S. (2011). Spatial modelling of soil-transmitted helminth infections in Kenya: A disease control planning tool. PLoS Neglected Tropical Diseases, 5(2), e958.

Regea, G. (2019). Prevalence of major gastrointestinal tract parasite of cattle at municipal Abattoir of Jimma Town, Oromia, South Western Ethiopia. Open Journal of Veterinary Medicine, 4(1), 36-44

Roepstorff, A., \& Murrell, K. D. (1997). Transmission dynamics of helminth parasites of pigs on continuous pasture: Ascaris suum and Trichuris suis. International Journal for Parasitology, 27(5), 563-572.

Skrjabin, K. I. (1928). Metod polnyh gel'mintologicheskih vskrytij pozvonochnyh, vkljuchaja cheloveka [The method of complete helminthological autopsy of vertebrates, including humans]. Moscow State University, Moscow (in Russian).

Skrjabin, K. I., Shikhobalova, N. P., \& Orlov, I. V. (1957). Osnovy nematodologii. Trihocefalidy i kapilljariidy zhivotnyh $i$ cheloveka i vyzyvaemye imi zabolevanija [Trichocephalids and capillariids of animals and man and the diseases caused by them. The essentials of nematodology]. Russian Academy of Sciences, Moscow (in Russian).

Storey, G. W., \& Phillips, R. A. (1985). The survival of parasite eggs throughout the soil profile. Parasitology, 91(3), 585-590.

Stroehlein, A. J, Young, N. D., Korhonen, P. K., Chang, B. C. H., Nejsum, P., Pozio, E., La Rosa, G., Sternberg, P. W., \& Gasser, R. B. (2017). Whipworm kinomes reflect a unique biology and adaptation to the host animal. International Journal for Parasitology, 47(13), 857-866.

Susana, Y., Suwanti, L. T., \& Suprihati, E. (2019). Identification and prevalence of gastrointestinal parasites in beef cattle in Siak Sri Indrapura, Riau, Indonesia. Indonesian Journal of Tropical and Infectious Disease, 7(6), 155-160.

Tshering, G., \& Dorji, N. (2013). Prevalence of gastrointestinal parasites in free range cattle: A case study in haa district, Bhutan. Journal of Animal Health and Production, 1(4), 36-37.

Tudor, P. (2015). Soil contamination with canine intestinal parasites eggs in the parks and shelter dogs from Bucharest area. Agriculture and Agricultural Science Procedia, 6, 387-391.

Van der Voort, M., Charlier, J., Lauwers, L., Vercruysse, J., Van Huylenbroeck, G. \& Van Meensel, J. (2013). Conceptual framework for analysing farm-specific economic effects of helminth infections in ruminants and control strategies. Preventive Veterinary Medicine, 109, 228-235.

Winarso, A., Satrija, F., \& Ridwan, Y. (2019). Prevalensi trichurosis pada sapi potong di Kecamatan Kasiman, Kabupaten Bojonegoro, Jawa Timur. Jurnal Kajian Veteriner, 3(2), 225-230

Yevstafieva, V. A., Kravchenko, S. O., Gutyj, B. V., Melnychuk, V. V., Kovalenko, P. N., \& Volovyk, L. B. (2019). Morphobiological analysis of Trichuris vulpis (Nematoda, Trichuridae), obtained from domestic dogs. Regulatory Mechanisms in Biosystems, 10(2), 165-171.

Yevstafieva, V. A., Melnichuk, V. V., Sharavara, T. A., Sirenko, E. V., Makarevich, N. A., Kutsenko, Y. P., \& Khlevnaya, G. S. (2018). Osobennosti embrional'nogo razvitija jaic nematod Trichuris skrjabini (Baskakov 1924), parazitiushhih u ovec [Specific features of embryonic development of Trichuris skrjabini (Baskakov, 1924) nematode eggs parasitizing in sheep]. An Agrarian Science of Euro-North-East, 62(1), 65-69 (in Russian).

Yevstafieva, V. A., Yuskiv, I. D., \& Melnychuk, V. V. (2015). An investigation of embryo and eggshell development in Trichuris suis (Nematoda, Trichuridae) under laboratory conditions. Vestnik Zoologii, 50(2), 173-178. 